"The branches to be included under these different departments we propose should be as follows:-

"I. Literature and Philology should comprise the subjects of Latin; Greek ; and English Literature ; together with one of the following subjects, viz.: Comparative Philology; Sanskrit; Hebrew; a Modern Language; Gaelic, with Celtic Philology. Questions on history and geography incidental to each subject should form part of the examination.

"Il. Philosophyshould include Logic and Metaphysics; Ethics and Psychology; and the Physiology of the Nervous System. The first two subjects are understood to embrace the History of Philosophy.

"III. Law and History should include Civil Law; either Constitutional Law or International Law; and Political Economy; together with the history of any one of the following groups, viz.: Greece and Rome; Modern Europe; Egypt, Syria, Palestine, and Arabia; India; Ancient and Modern America.

"IV. Mathematical Science should embrace Mathematics, pure and applied; Natural Philosophy; and Physical Astronomy.

"V. Natural Science should comprehend four groups, viz. :- (I) Applied Mathematics, Natural. Philosophy, and Chemistry; (2) Natural Philosophy, Chemistry and Physiology ; (3) Physiology, Botany, and Zoology ; (4) Natural Philosophy, Chemistry, and Geology. A candidate should be allowed to take any two of these four groups; and the practical working of the arrangement would be that Natural Philosophy and Chemistry would be compulsory, while any option would be given between the mathematical and the morphological sciences.

"It may be explained that the subjects of examination in the sciences comprehended in Department $V$. are such as are required in the first Bachelor of Science examination as detailed in the Calendars of the Universities of Edinburgh and London (1877). The purpose we have had in subdividing the subjects of Department $V$, into groups has been, in the first place, to ensure a sound acquaintance with Physics and Chemistry, which lie at the foundation of all natural science; and, in the second place, so much being secured, to give fair play to indiviaual intellectual tastes and peculiarities. It is rare to find a man equally capable of dealing with long chains of abstract reasoning, or with experimental research, and of observing and remembering the analogies and differences of form. The scientific aptitude, when strongly marked, is either for mathematics, for experimental investigation, or for morphology, rarely for all three.

"In regard to the scientific subjects, mere book knowledge should not suffice; practical work in the laboratory should be essential."

We are much mistaken if this Report does not produce great irritation, amounting in many quarters to white heat at least, and determined opposition. The dry husks of speculative "philosophy" which, feebly existent even in the present day (like Bunyan's Pope and Pagan), formed so large an ingredient in the mental pabulum of Scottish students in the past, are doomed to "cease from troubling":- but they will die hard. In their place will come the still oppressed truths of modern science, and the legitimate speculations which Experience and mathematical power alone can enable the human mind to originate and develop.

\section{SUN-SPOTS AND RAINFALL}

THE paper which we print from Mr. Meldrum this 1 week, appearing as it does within a few days of the debate in the House of Commons on the Indian Famine expenditure, is one which should be interesting to many besides professed meteorologists. It will, for one thing, enable even the most unscientific among us to see the manner in which men of science are striving to arrive at the truths of nature the while the average Member of Parliament only refers to their labours in order to sneer at them even when their results may elucidate a question of high national importance.

Granting that the Member for Cambridge comes up to the average of our legislators, let us see how he distinguished himself on Tuesday. In his indictment of the policy of Sir John Strachey, he was unwise enough to touch on the question of the connection between sun-spots and the Indian rainfall. "It appeared that, according to the astronomer to the government at Madras, the absence of several important spots (sic) on the sun's disc was connected.with the retarded rainfall." It is clear from this, we think, that Mr. Smollett, in his ignorance of all things solar, instead of taking a little trouble to inform himself, has buil up a mental image of the physics of our central luminary, by likening it to the house of which we will grant again he is one of the most prominent units. The cause of the sun-spot minimum appears to him to be that at this time "several important spots"-let us say the Smolletts of the sun-are in the tea-room or at dinner, anyhow they are absent from the division, and the opposition carries the day-that is, if Mr. Pogson is right, but he proceeds to show that Mr. Pogson is wrong.

Dr. Lyon Playfair, as was to be expected, put this matter right before the house. He stated that "it was established that famines in India came at periods when sun-spots were not visible. Out of twenty-two great observatories of the world it had been shown in eighteen that the minimum rainfall was at times when there were no spots on the sun. That was as true in Edinburgh as in Madras, in St. Petersburg as in Australia. It was therefore essential for the Government of India to take that into consideration in calculating as to when famines were likely to occur. The Secretary of State for India had acted wisely in sending out photographers to the Himalayas to take photographs of the sun, and having seen some of those, he was sorry to say that on none which he had seen were spots to be detected." As Dr. Playfair is not in the habit of making statements without getting up his case, we may be thankful to Mr. Smollett for the sneer which called Dr. Playfair up.

Mr. Meldrum's communication contains a very condensed reference to his memoir on Sun-spots and Rainfall recently presented by him to the Meteorological Society of the Mauritius, a memoir which goes far to complete one portion of that magnificent edifice, the erection of which was foreseen by Sir Wm. Herschel at the beginning of the present century.

In this important paper Mr. Meldrum, than whom there exists no higher authority, states that the result of his seven years' work has been to convince him that the connection between sun-spots and rainfall is as intimate as that between sun-spots and terrestrial magnetism; and that having regard to the number of cycles at our disposal we should be as justified in rejecting the diurnal oscillation of the barometer as the curve along the hills and hollows of which the maximum and minimum rainfalls of the world lie.

This result of course will be received with incredulity 
by many-and for many reasons. In the first place the enormous variation in the solar activity is a fact only fully realised by very few. Men grown old in the service of science are as a rule as little anxious to receive new ideas as men grown old in any other of the world's activities, and further and more than this, in the case of many there is what has recently been happily termed "a paralysis of the imagination "-a thing far removed from scientific caution-which may and indeed certainly would do much harm to scientific progress if those afflicted with it had any chance of having the exclusive say in the matter.

Now that things have arrived at this stage it is well to bring to the front some extracts from those papers of Sir Wm. Herschel's to which reference has already been made, to show the wonderful prescience of the man, and also to give an idea of the valuable time which has been lost by the neglect, during three-quarters of a century, to take in hand the work from which he predicted such a rich harvest of benefits would follow.

His first reference to the changes going on in the sun was made in $1801 .^{1}$ He writes :-

"On a former occasion I have shown that we have great reason to look upon the sun as a most magnificent habitable globe; and, frem the observations which will be related in this paper, it will now be seen that all argu. ments we have used before are not only confirmed, but that we are encouraged to go a considerable step further in the investigation of the physical and planetary construction of the sun. The influence of this eminent body on the globe we inhabit is so great and so widely diffused that it becomes almost a duty for us to study the operations which are carried on upon the solar surface. Since light and heat are so essential to our well-being, it must certainly be right of us to look into the source from whence they are derived, in order to see whether some material advantage may not be drawn from a thorough acquaintance with the causes from which they originate.

"A similar motive engaged the Egyptians formerly to study and watch the motions of the Nile and to construct instruments for measuring its rise with accuracy. They knew very well that it was not in their power to add one single inch to the flowing waters of that wonderful river; and so, in the case of the sun's influence, we are likewise fully a ware that we shall never be able to occasion the least alteration in the operations which are carried on in the solar atmosphere. But if the Egyptians could avail themselves of the indications of a good Nilometer, what should hinder us from drawing as profitable consequences from solar observations? We are not only in possession of photometers and thermometers, by which we can measure from time to time the light and heat actually received from the sun, but have more especially telescopes, that may lead us to a discovery of the causes which dispose the sun to emit more or less copiously the rays which occasion either of them; and if we should even fail in this respect, we may at least succeed in becoming acquainted with certain symptoms or indications, from which some judgment might be formed of the temperature of the seasons we are likely to have.

"Perhaps our confidence in solar observations made with this view, might not exceed that which we now place on the indications of a good barometer with regard to rain or fair weather; but even then a probability of a hot summer, or its contrary, would always be of greater consequence than the expectation of a few fair or rainy days.

I "Observations tending to investigate the Nature of the Sun in order to find the Causes or Symptoms of its Variable Emission of Light and Heat; with Remarks on the Use that may possibly be drawn from Solar Observations." By William Herschel, LL.D., F.R.S., read April 16, x80x.
"It will be easily perceived that in order to obtain such an intimate knowledge of the sun as that which is required for the purpose here pointed out, a true information must be first procured of all the phenomena which usually appear on its surface."

He then gives those wonderful observations which make this paper the basis of our knowledge of the smaller units of the sun's surface, and then sums up as follows :-

"From these two last sets of observations, one of which establishes the scarcity of the luminous clouds, while the other shows their great abundance, I think we may reasonably conchude that there must be a manifest difference in the emission of light and heat from the sun. It appears to me, if I may be permitted the metaphor, that our sun has for some time past been labouring under an indisposition, from which it is now on a fair way of recovering.

"An application of the foregoing method, however, even if we were perfectly assured of its being weil founded, will still remain attended with considerable difficulties. We see how, in that simple instrument the barometer, our expectations of rain and fair weather are only to be had by a consideration of many circumstances besides its actual elevation at the moment of inspection. The tides also present us with the most complicated varieties in their greatest elevation, as well as in the time when they happen on the coasts of different parts of the globe. The simplicity of their cause, the solar and lunar attractions we might have expected, would have precluded every extraordinary and seemingly discordant resulss.

"In a much higher degree may the influence of more or less light from the sun be lichble to produce a griat variety in the severity or milliness of the seissons of different climates and under different local circumsitumies, yet when many things which are already known to afrect the temperature of different countries and others which future attention may still discover, come to be properly combined with the results we propose to draw from solar observations, we may possibly find this subject less intricate than we might apprehend on a first view of it.

"If for instance we should have a warm summer in this country when phenomena observed in the sun indicate the expectation of it, I should by no means consider it as an unsurmountable objection, if it were shown that in another country the weather had not been so favourable.

"And if it were generally found that our prognostication from solar observations held good in any one given place I should be ready to say that with proper modifications they would equally succeed in every other situation.

"Before we can generalise the influence of a certain cause we ought to confine our experiment to one permanent situation, where local circumstances may be supposed to act nearly alike at all times which will remove a number of difficulties."

This was in April ; in May he read another paper. ${ }^{1}$

"Having brought the solar observations relating to the symptoms of copious emission of the light and heat of the sun to the and of March I gave them continued in this paper to the 3 rd of May. It will be seen that my expectations of the continuance of the symptoms which I supposed favourable to such emissions, have hitherto been sufficiently verified; and by comparing the phenomena I have reported with the corresponding mildness of the season, my arguments will receive a considerable support.

"I have given the following observations without delay as containing an outline of the method we ought to pursue in order to establish the principles which have been pointed out in my former paper. But we need not in future be at a

I "Additional Observations tending to Investigate the Symptoms of the Variable Emissions of the Light and Heat of the Sun ; with Trials to set aside darkening Glasses by Transmitting the Solar Rays through Liquids, and a few Remarks to Remove Objections that might be made against some of the Arguments contained in the former Paper," by William Herschel
LL.D., f.R.S. Read May $x_{4}$, r8or. 
loss how to come at the truth of the current temperature of this climate as the thermometrical observations which are now regularly published in the Philosopliical Transactions can furnish us with a proper standard with which the solar phenomena may be compared. This leads me to remark that although I have in my first paper sufficiently noticed the want of proper criterion for ascertaining the temperature of the early periods where the sun has been recorded to have been without spots, and have also referred to future observations for showing whether a due distribution of dry and wet weather with other circumstances which are known to favour the vegetation of corn, do or do not require a certain regular emission of the solar beams, yet I might still have added that the actual object we have in view is perfectly independent of the result of any observations that may hereafter be made on the favourable or defective vegetation of grain in this or in any other climate... It may be hoped that some advantage $\mathrm{m} 1 \mathrm{y}$ be derived even in agricultural economy, from an improved knowledge of the nature of the sun and of the causes or symptoms of its emitting light or heat more or less copiously."

It perhaps will be news to many that the idea of a possible connecttion between sun-spots and rainfall which has been represented as a modern idea, may really be credited to a man whose chief work was done in the last century.

\section{DARWIN'S "DIFFERENT FORMS OF FLOWERS"}

The Different Forms of Flowers on Plants of the same Species. By Charles Darwin, M.A., F.R.S. (London: John Murray, 1877.)

THIS is another of the remarkable series of volumes 1 in which Mr. Darwin has given us the extremely valuable results of his researches in the vegetable side of biology. Mr. Darwin's method of investigation would in itself be a very interesting subject for consideration. It is, however, sufficient to point out that its characteristic feature is the combined attack upon a given problem from both its morphological and physiological aspects. This method Mr. Darwin employs with consummate success, and in turning over the pages of the present booka considerable part of which has been before the world for more than a decade without being materially impugned-one is almost distracted from the intrinsic interest of the facts and speculations by the sagacity with which the research is carried on, and the skill with which the results are marshalled for our information. It is peculiarly worthy of notice in the present volume how the reader is allowed, in studying Mr. Darwin's pages, to form his own hypotheses in explanation of the facts, only to be compelled in due course, as the narrative proceeds, to admit that such hypotheses are utterly untenable. There is no impression so curious as to find oneself so distinctly under the hands of a master, and to realise that the calm flow of the argument proceeds over the débris of objections and difficulties which are found to be already comminuted as soon as one attempts to give them any definite form.

It would be quite impossible to treat, in the short space at our disposal,.all that calls for notice in the present volume. Commencing with a short introduction, the body of the book falls into three divisions. The first treats of heterostyled plants, and contains in a connected form the substance of Mr. Darwin's various papers com- municated to the Linnean Society. The second and third divisions are much shorter, and treat respectively of the passage of hermaphrodite into diccious plants, and of cleistogamic flowers.

As has been already remarked, Mr. Darwin's researches on what are now termed heterostyled plants have been common scientific property for many years, and have filtered down into the current text-books. The seventh and eighth chapters are therefore the essentially new part of the book, and these we shall more particularly consider.

The vast majority of flowering plants are, as is well known, hermaphrodite, that is to say, they contain within the same floral envelopes both male and female organs. The governing principle in the morphological adaptations of flowers is apparently to escape the obvious consequences of such juxtaposition and evade self-fertilisation. This is effected either by theirbeing dichogamic-that is the sexual organs in any one flower maturing at different times, or by their being entomophilous - that is calling in the intervention of insects to carry the pollen of one flower to the stigma of another, or by their being heterostyled-that is by the flower being modified in two or three ways, admitting of a certain number of reciprocal modes of fertilisation which are legitimate, and of others which are distinguished as illegitimate, and are more or less sterile.

Each of these modes of avoiding self-fertilisation practically sets up a functional separation of the sexes, and it might seem that the cases in which this separation is siructurally accomplished are its natural sequence. Mr. Darwin points out, however, very conclusively that this is by no means the case.

"There is much difficulty in understanding why hermaphrodite plants should ever have been rendered diœcious. There would be no such conversion un!ess pollen was already carried regularly by insects or by the wind from one individual to the other, for otherwise every step towards diceciousness would lead towards sterility. As we must assume that cross-fertilisation was assured before an hermaphrodite could be changed into a dicecious plant, we may conclude that the conversion has not been effected for the sake of gaining the great benefits which follow from cross-fertilisation."

Mr. Darwin is led to find an explanation in the advantage to the plant in the diminished strain of producing sexual organs of only one kind instead of both. Aud the process of manufacturing dicecious plants is one which can be actually seen in process. The cultivated strawberry under the infuence of the American climate is a marked instance. In such cases the hermaphrodite state can be traced into the dicecious with every intermediate grade. The ultimate fate of heterostyled plants is perhap s to be converted into diøcious ones, and in this instance the change would be more immediate and with fewer connecting links. The functional diversity already exists and the corresponding suppression of the sexual organs is all that is needed to render it complete.

The concluding chapter on cleistogamic flowers certainly does not yield in interest to any preceding portion of the book. The existence of these curiously-modified structures has long been known, but it is only within the last twenty years that they have been attentively studied, and Mr. Darwin's account, is a very masterly discussion of all that has been written on a very puzzling subject, tested 